\title{
ANALISIS MUTU LAYANAN UNIT REKAM MEDIS BERDASARKAN KEPUASAN PELANGGAN INTERNAL DENGAN MENGGUNAKAN METODE SERVICE QUALITY DAN QUALITY FUNCTION DEPLOYMEN DI RSU IPI MEDAN TAHUN 2018
}

\author{
${ }^{1}$ Siti Permata Sari Lubis, ${ }^{2}$ Putri Zebua \\ ${ }^{1}$ Dosen STIKes Imelda, Jalan Bilal Nomor 52 Medan; ${ }^{2}$ Alumni APIKES Imelda \\ E-mail: sity_cyan@gmail.com
}

\begin{abstract}
ABSTRAK
Penyelenggaraan rekam medis yang menjadi salah satu indikator mutu pelayanan rumah sakit. Untuk meningkatkan kualitas layanan, yaitu kepuasan konsumen maka dilakukan analisa dengan menggunakan metode Service Quality dengan teknik Quality Function Deployment (QFD). Tujuan penelitian ini Untuk menganalisis mutu layanan Unit rekam medis di RSU IPI Medan berdasarkan kepuasan pelanggan internal dengan metode service quality dan quality function deploymen. Penelitian ini menggunakan jenis penelitian deskriptif yang dilakukan pada bulan juni-juli 2018 dengan sampel 44 pelanggan internal dari 220 pelanggan internal RS. Hasil gab Ruang Penyimpanan yang luas (-136), Jumlah Pegawai (-97), Keamanan penyimpanan berkas rekam medis (-94), Letak gedung (URM) yang strategis dari rawat inap (-83), Kesesuai informasi (-57). Berdasarkan House of Quality tool dari Quality Function Deployment, perbaikan yang direkomendasikan berdasarkan gab terbesar. Kepada pihak rumah sakit diharapkan memenuhi kebutuhan pelanggan internal untuk meningkatkan mutu layanan unit rekam medis.
\end{abstract}

Kata Kunci $\quad$ : Service Quality, Quality Function Deployment, House of Quality

\section{PENDAHULUAN}

Sesuai dengan UU No.36 tahun 2009 bahwa untuk menyelenggarakan upaya kesehataan yang efektif dan efesien maka di butuhkan adanya sistem informasi kesehatan. Sistem informasi kesehatan yang terpadu dan mampu menghasilkan data atau informasi yang lengkap, akurat, relevan dan tepat waktu merupakan salah satu komponen yang sangat penting dalam pengambilan keputusan di bidang kesehatan. Dalam ruang lingkup rumah sakit, penyelenggaraan sistem informasi kesehatan harus dilakukan secara menyeluruh di semua unit pelayanaan yang ada untuk mendukung pencapaaian kualitas pelayanan yang bermutu.

Unit rekam medis salah satu gerbang terdepan dalam layanan rumah sakit, sehingga dapat di jadikan pula salah satu ukuran kepuasan bagi konsumen kesehatan baik pelanggan internal maupun pelanggan external. Tetapi aspek-aspek yang mempengaruhi kepuasan pelanggan internal berbeda dengan pelanggan external, karena jenis pelanggan internal yang banyak (Pohan,2015).
Untuk meningkatkan kualitas layanan, yaitu kepuasan konsumen maka dilakukan analisa dengan menggunakan metode Service Quality dan Quality Function Deployment (QFD). Service Quality salah satu metode mengetahui kualitas layanan berdasarkan hasil kesenjangan $G a b$, lalu akan di lanjutkan dengan metode QFD yaitu pembuatan rumah kualitas (house of quality) untuk menjawab kebutuhan konsumen. QFD berusaha menerjemahkan apa yang dibutuhkan pelanggan menjadi apa yang akan dihasilkan oleh organisasi, memungkinkan organisasi memprioritaskan kebutuhan pelanggan, QFD juga merupakan praktik menuju perbaikan proses yang dapat memungkinkan organisasi mencapai harapan pelanggan (Wijaya,2018).

Layanan kesehatan yang bermutu tidak mungkin merupakan hasil kerja seorang petugas kesehatan saja, masing-masing petugas kesehatan itu akan menjadi konsumen dari petugas kesehatan lainnya. Sehingga bisa dikatakan bahwa pasien merupakan pelanggan layanan kesehatan, tetapi pasien dalam hal ini hanya merupakan salah satu jenis pelanggan. Pelanggan kesehatan merupakan semua 
orang yang sehari-hari melakukan kontak dengan layanan kesehatan (Pohan,2015).

Berdasarkan pengertian ini dikenal dua macam pelanggan, yaitu Pelanggan Internal dan Pelanggan Eksternal. Pelanggan internal adalah semua orang yang berkerja dalam organisasi layanan kesehatan dan pelanggan internal ini sangat penting karena harus bekerja dalam organisasi layanan kesehatan yang bermutu, sedangkan pelanggan eksternal adalah orang yang berada di luar organisasi layanan kesehatan yang memperoleh layanan kesehatan yang dihasilkan oleh organisasi layanan kesehatan. Pelanggan eksternal ini meliputi pasien, keluarganya, dokter praktik swasta, dokter tamu, pemasok dan kontraktor, serta pekerja sukarela (Pohan,2015).

Hasil wawancara yang dilakukan saat survei penelitian kepada pelanggan internal Rumah Sakit Umum Imelda Pekerja Indonesia (RSU IPI) Medan mengatakan bahwa penyediaan berkas rekam medis yang masih lama, ruang penyimpanan rekam medis kurang luas, jumlah petugas rekam medis masih kurang serta kurangnya komunikasi petugas rekam medis, perawat dan dokter.

Dari permasalahan diatas, penulis tertatik untuk mengetahui sejauh mana mutu pelayanan unit rekam medis berdasarkan kepuasan pelanggan internal di Rumah Sakit IPI Medan dengan mengambil judul "Analisis Mutu Layanan Unit Rekam Medis Berdasarkan Kepuasan Pelanggan Internal dengan menggunakan Metode Service Quality dan Quality Function Deployement Di RSU IPI Medan”.

\section{Rumusan Masalah}

Dari latar belakang masalah serta identifikasi masalah, maka didapatkan rumusan masalah yaitu Bagaimana mutu layanan unit rekam medis di RSU IPI Medan berdasarkan kepuasan pelanggan internal dengan menggunakan metode service quality dan quality function deploymen.

\section{Tujuan Penelitian}

Untuk menganalisis mutu layanan Unit rekam medis di RSU IPI Medan berdasarkan kepuasan pelanggan internal dengan menggunakan metode service quality dan quality function deploymen.

\section{Manfaat Penelitian}

1. Bagi petugas Unit rekam medis agar dapat meningkatkan mutu pelayanan bagi pelanggan internal.

2. Bagi Rumah Sakit dengan hasil penelitian ini bisa digunakan sebagai upaya rumah sakit untuk meningkatkan mutu pelayanan.

3. Bagi peneliti untuk menambahkan ilmu pengetahuan khususnya menerapkan ilmu yang di dapat selama mengikuti pendidikan Manajemen Rumah Sakit.

\section{METODE}

\section{Jenis Penelitian}

Jenis penelitian deskriptif dengan pendekatan penelitian kuantitatif (Sugiyono, 2013).

\section{Tempat Penelitian}

Penelitian ini dilakukan di Rumah Sakit Umum Imelda Pekerja Indonesia Medan yang beralamat Jl. Bilal No. 24 Pulo Brayan Darat I Medan.

\section{Populasi}

Populasi dalam penelitian ini adalah seluruh pelanggan internal rumah sakit pegawai perawat, pegawai rekam medis, dan dokter tahun 2018 dengan jumlah 220 pegawai.

\section{Sampel}

Sampel pada penelitian ini sebanyak 44 pelanggan internal di RSU IPI Medan dengan menggunakan rumus Arikunto sebesar 20\% (Novi, 2010).

$\mathrm{n}=20 \% \times \mathrm{N}$

Keterangan :

$\mathrm{n}$ : besar sampel

$\mathrm{N}$ : besar populasi

Berdasarkan rumus tersebut, jumlah sampel yang diperoleh adalah sebagai berikut :

$$
\begin{aligned}
& \mathrm{n}=20 \% \times \mathrm{N} \\
& \mathrm{n}=0,2 \times 220 \\
& \mathrm{n}=44
\end{aligned}
$$

Jadi, jumlah sampel minimal yang diperlukan dalam penelitian ini adalah berjumlah 44 responden.

\section{Teknik Sampling}


Probability Simple Random Sampling adalah pengambilan sampel sederhana dilakukan secara acak tanpa memperhatikan strata yang ada dalam populasi itu. Populasi penelitian sebanyak 220 pelanggan internal yaitu pegawai perawat sebanyak 134, pegawai rekam medis sebanyak 16 dan dokter sebanyak 70. Sampel disetiap ruangan pegawai dihitung berdasarkan perhitungan proporsi (Novi, 2010) :

Sampel ruangan $\left(n^{\prime \prime}\right)=$ $\frac{\text { populasi ruangan }}{\text { populasi penelitian }} \times n$

$n$ "Perawat $=\frac{134}{220} \times 44=26,8=27$

$n$ " Rekam Medis $=\frac{16}{220} \times 44=3,2=3$

$n$ "Dokter $=\frac{70}{220} \times 44=14$

Jadi, jumlah sampel pegawai perawat, rekam medis dan dokter masing-masing yaitu, Pegawai Perawat sebanyak 27 orang, pegawai rekam medis sebanyak 3 orang dan dokter sebanyak 14 orang.

\section{Instrumen Penelitian}

Instrumen yang akan digunakan dalam penelitian ini adalah Kuesioner. Kuesioner yang di susun merupakan kuesioner tertutup untuk memperoleh informasi dari reponden tentang mutu layanan unit rekam medis berdasarkan kepuasan pelanggan internal (Isgianto, 2009).

\section{Cara Pengumpulan Data}

Cara pengumpulan data pada penelitian ini adalah sebagai berikut (Notoatmodjo,2012) :

\section{Data Primer}

Data primer merupakan data yang diperoleh secara langsung dari objek yang diteliti. Data primer diperoleh dari wawancara yang dilakukan kepada petugas berdasarkan kuesinoner yang telah ada.

2. Data Sekunder

Data sekunder merupakan data yand diperoleh dari sumber yang tidak langsung, biasanya berupa data dokumen dan arsip-arsip resmis. Data sekunder pada penelitian ini diperoleh dari Kantor Administrasi RS IPI Medan.

\section{Teknik Pengolahan Data}

Setelah data terkumpul maka dilakukan pengolahan data, data diolah secara (Notoatmodjo, 2012).
1. Editing
2. Coding
3. Entry (processing)
4. Tabulasi Data

\section{Analisis Data}

Analisis data digunakan untuk menyederhanakan data kedalam bentuk yang lebih mudah dibaca dan dimengerti. Analisa data dilakukan secara deskriptif yaitu menggambarkan data yang terkumpul sebagaimana adanya tanpa bermaksud membuat kesimpulan yang berlaku untuk umum atau generalisasi (Isgiyanto,2009).

\section{HASIL}

\section{Metode Service Quality}

Penentuan Gab dengan rumus $\mathrm{Q}=\mathrm{P}-\mathrm{E}$ (Pohan,2018)

Dimana $\mathrm{Q}=$ quality of service (kualitas layanan)

$\mathrm{P}=$ Persepsi

$\mathrm{E}=$ Ekspekstasi (Harapan)

Tabel 1. Kesenjangan Atribut Layanan Di Unit Rekam Medis

\begin{tabular}{llcc}
\hline \multicolumn{1}{c}{ Dimensi } & \multicolumn{1}{c}{ Atribut Layanan } & \multicolumn{1}{c}{ Customer Satisfaction } \\
\cline { 2 - 4 } $\begin{array}{l}\text { Tangibles } \\
\text { (Bukti Langsung) }\end{array}$ & 1.Letak gedung (URM) yang st rategis dari rawat jalan & 140 & 192 \\
\cline { 2 - 4 } & 2.Letak gedung (URM) yang strategis dari rawat inap & 126 & 209 \\
\cline { 2 - 4 } & 3.Ruang penyimpanan yang luas & 76 & 212 \\
\cline { 2 - 4 } & 4. Perlengkapan rekam medis & 147 & 201 \\
\cline { 2 - 4 } & 5.Jumlah pegawai & 160 & 208 \\
\hline Kehandalan & 7.sarana komunikasi & 152 & 186 \\
\hline reliability) & 8.Kecepatan penyediaan berkas RM & 156 & 212 \\
\hline Daya tanggap & 9.kesesuaian informasi & 148 & 205 \\
\hline
\end{tabular}




\begin{tabular}{llcc}
\hline (responsiveness) & 10.Kesiapan petugas rekam medis & 162 & 210 \\
\cline { 2 - 4 } & 11.ketepatan dalam pengambilan berkas RM & 176 & 180 \\
\cline { 2 - 4 } Jaminan & 12.keramahan petugas & 159 & 181 \\
(assurance) & 13.keamanan penyimpanan berkas RM & 85 & 179 \\
\cline { 2 - 4 } & 14.sikap petugas dalam menghadapi perawat & 161 & 210 \\
\hline Empati & 16.kecepatan dalam pemberian informasi dan penyediaan berkas & 163 & 214 \\
\cline { 2 - 4 } & 17. Komunikasi & 186 & 213 \\
\hline
\end{tabular}

Rata-rata $g a b$ masing-masing dimensi dihitung dengan menjumlahkan nilai gab pada masing-masing dimensi kemudian dibagi dengan banyaknya jumlah atribut pada masing-masing dimensi, yang diperhitungkan sebagai berikut:

Tangibles (Bukti Langsung) $=(-52)+(-83)$ $+(-136)+(-80)+(-97)+(-80)=-528: 6=$ $-88$

Dengan cara yang sama maka kita dapat mengetahui rata-rata gab pada masing-masing dimensi sebagai berikut.

Tabel 2. Nilai Rata-Rata Gab Tiap Dimensi Service Quality

\begin{tabular}{llc}
\hline No & \multicolumn{1}{c}{ Dimensi } & Nilai Rata \\
\hline 1 & Tangibles (Bukti Langsung) & -88 \\
\hline 2 & Kehandalan (reliability) & -122 \\
\hline 3 & Daya tanggap (responsiveness) & -217 \\
\hline 4 & Jaminan (assurance) & -245 \\
\hline 5 & Empati & -155 \\
\hline
\end{tabular}

\section{Metode Quality Function Deployment} (QFD)

\section{Penyusunan Relationship Matrix}

1. Penyusunan Customer Needs (What's) Atribut pelayanan yang harus diperbaiki berdasarkan tingkat kepuasan dibawah yaitu $5 \mathrm{gab}$ tertinggi dari harapan pelanggan internal, anatara lain :

a. Ruang Penyimpanan yang luas

b. Jumlah Pegawai

c. Keamanan penyimpanan berkas rekam medis

d. Letak gedung (URM) yang strategis dari rawat inap

e. Kesesuai informasi.

2. Penetapan Hows descriptions)

Berdasarkan customer needs yang telah ditentukan, maka dapat ditetapkan beberapa respon teknik sebagai berikut :

a. Memperluas ruang penyimpanan

b. Penambahan jumlah pegawai

tecnical c. Melengkapi kebutuhan penyimpanan berkas rekam medis

d. Pengadaan letak URM ditempat strategis

e. Menjalin komunikasi yang baik antar pelanggan internal

3. Mengembangkan hubungan antara Matrix Whats dan Matrix Hows

Matrix Whats merupakan pertanyaan dan matriks hows merupakan jawabanjawaban, sehingga dari kedua matriks ini aka terjadi hubungan. Jika hubungan antara matrik. Whats dan Hows sangat kuat maka nilainya 9 , jika hubungannya sedang maka nilainya 3, dan jika hubungannya kecil maka nilainya 1 . Matriks whats dengan hows dapat dilihat pada gambar berikut:

Gambar 1. Matrik antara Whats dengan Hows

Keterangan :

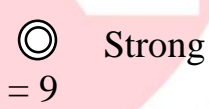

\section{Moderate} $=3$

\section{$\triangle$ Weak \\ $=1$}

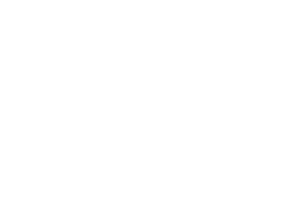

Teknikal Descriptor (hows)

\begin{tabular}{|c|c|c|c|c|}
\hline 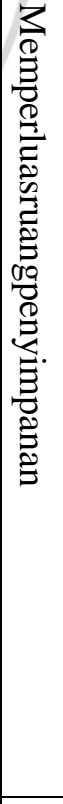 & 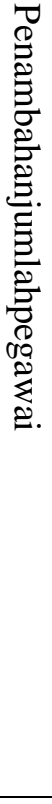 & 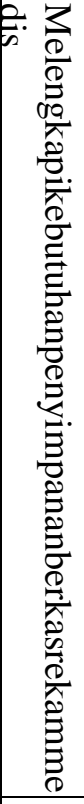 & 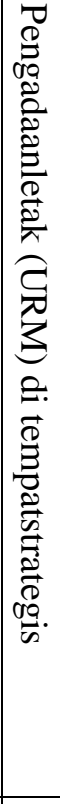 & 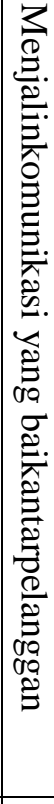 \\
\hline (2) & & & & \\
\hline & (2) & & & \\
\hline 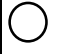 & & (2) & & \\
\hline
\end{tabular}




\begin{tabular}{|l|l|l|l|l|l|l|}
\hline $\begin{array}{l}\text { berkas rekam } \\
\text { medis }\end{array}$ & & & & & \\
\hline $\begin{array}{l}\text { Letakgedung } \\
\text { (URM) dari } \\
\text { rawat inap }\end{array}$ & & & & 0 & \\
\hline $\begin{array}{l}\text { Kesesuaian } \\
\text { informasi }\end{array}$ & & & & & $\bigcirc$ \\
\hline
\end{tabular}

Dari gambar diatas dapat disimpulkan bahwa atribut yang memiliki hubungan yang sangat kuat adalah

a. Ruang penyimpanan yang luas sangat kuat hubungannya dengan memperluas ruang penyimpanan.

b. Jumlah pegawai sangat kuat hubungannya dengan penambahan jumlah pegawai.

c. Keamanan penyimpanan berkas rekam medis sangat kuat hubungannya dengan melengkapi kebutuhan penyimpanan berkas rekam medis.

d. Letak gedung (URM) snagat kuat hubungannya dengan pengadaan letak URM di tempat strategis.

e. Kesesuaian Informasi sangat kuat hubungannya dengan menjalin komunikasi yang baik antar pelanggan internal.

4. Mengembangkan hubungan antar matrik Hows, bahwa atribut yang memiliki hubungan yang sangat kuat adalah

a. Ruang penyimpanan yang luas sangat kuat hubungannya dengan memperluas ruang penyimpanan.

b. Jumlah pegawai sangat kuat hubungannya dengan penambahan jumlah pegawai.

c. Keamanan penyimpanan berkas rekam medis sangat kuat hubungannya dengan melengkapi kebutuhan penyimpanan berkas rekam medis.

d. Letak gedung (URM) snagat kuat hubungannya dengan pengadaan letak URM di tempat strategis.

e. Kesesuaian Informasi sangat kuat hubungannya dengan menjalin komunikasi yang baik antar pelanggan internal.

5. Mengembangkan hubungan antar matrik Hows
Gambar 2. Hubungan Antar Matrik Hows

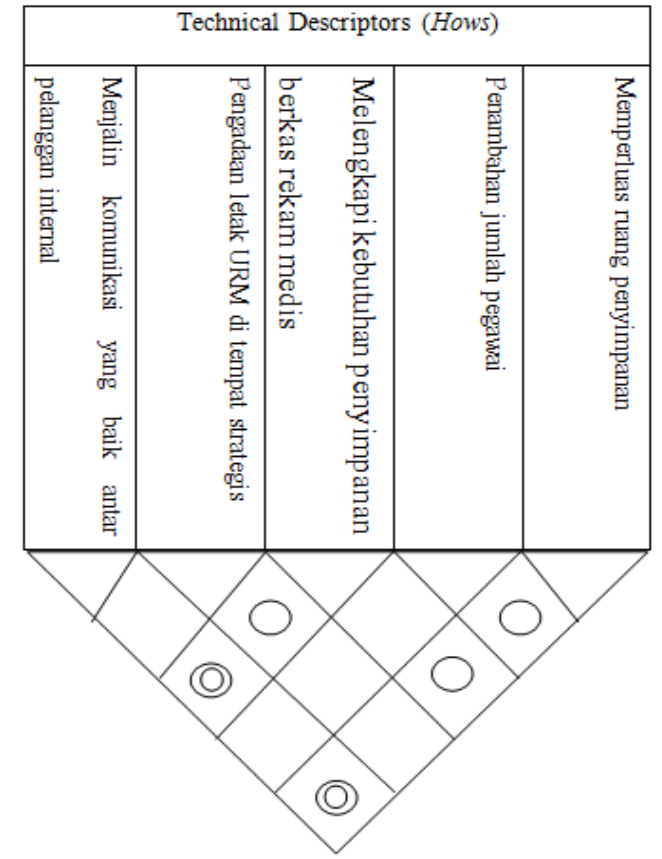

Dari gambar diatas dapat disimpulkan bahwa atribut Hows yang memiliki pengaruh positif yang kuat adalah

a. Memperluas ruang penyimpanan, penambahan jumlah pegawai dan melengkapi kebutuhan penyimpanan berkas rekam medis.

b. Seluruh atribut memiliki pengaruh yang sangat kuat untuk meningkatkan kepuasan pelanggan internal di RS IPI Medan.

\section{PEMBAHASAN}

\section{Analisis Service Quality}

Hasilnya telah dijelaskan pada konsep Service Quality antara harapan dan kepuasan pelanggan, yakni mereka merasa tidak puas terhadap pelayanan yang telah diberikan oleh penyedia jasa layanan. Maka terdapat 5 angka tertinggi gab yaitu : Ruang Penyimpanan yang luas (-136), Jumlah Pegawai (-97), Keamanan penyimpanan berkas rekam medis (-94), Letak gedung (URM) dari unit rawat inap (-83) dan Kesesuai informasi (-57).

Analisis bagian matrix service quality akan menentukan kebutuhan apa yang diprioritaskan oleh pelanggan, yaitu dengan menganalisis kebutuhan pelanggan menurut kesenjangan ( $g a b)$ tingkat kualitas. Penentuan kebutuhan pelanggan berdasarkan tingkat kesenjangan kualitas. Para pelanggan internal menilai bagaimana 
pelayanan yang telah diberikan atau diterima dengan membandingkannya dengan yang diinginkan oleh pelanggan internal. Apabila nilai kepuasan yang telah diterima sama atau lebih besar dari yang diinginkan atau diharapkan, berarti atribut layanan yang diberikan lebih kecil dari yang pelanggan merasa tidak puas terhadap atribut layanan yang bersangkutan (Wijaya,2018).

\section{Analisis Metode Quality Function Deployment}

Setelah melakukan analisis gab menggunakan service quality dan menentukan $5 \mathrm{gab}$ terbesar dari perbedaan kepuasan dan harapan pelanggan internal RS, selanjutnya adalah melakukan analisis QFD. Salah satu hal penting dalam QFD yaitu House of Quality (HOQ), tahap penyusunan nya sebagai berikut:

1. Hasil penelitian penyimpanan berkas rekam medis memiliki gab terbesar dan dengan menjawab What dari kebutuhan pelanggan internal maka Hows menjawab dengan memperluas penyimpanan berkas rekam medis. Penyimpanan dokumen rekam medis mempunyai arti yang sangat penting sehubungann dengan riwayat penyakit pasien dan kerahasiaan yang terkandung didalamnya. Oleh karena ini cara penyimpanan pun harus di atur sedemikian rupa sehingga terjaga rahasianya (Wiguna, 2015).

2. Hasil penelitian jumlah petugas rekam medis di RS IPI Medan yang tersedia 16 orang. Menurut Peraturan Bersama Menteri Kesehatan dan Kepala Badan Kepegawaian Negara (2013), formasi jabatan fungsional perekam medis untuk Rumah Sakit Umum kelas B adalah terampil 45 orang dan Ahli 10 orang.

3. Hasil penelitian kepuasan pelanggan internal dengan keamaan peyimpanan berkas rekam medis angka ketiga dari $g a b$ terbesar. Sehingga dibutuhkan lah kelengkapan untuk kebutuhan penyimpanan berkas rekam medis. Rekam medis milik sarana pelayanan kesehatan dan isi rekam medis merupakan milik pasien, maka rumah sakit wajib menjaga kerahasiaan isi dokumen rekam medis. Pelayanan perawatan medis tidak dapat dijalankan dengan efektif jika bilaman data rekam medis rusak atau hilang karena adanya kesinambungan informasi medis.

4. Hasil penelitian kepuasan pelanggan internal dengan letak unit rekam medis dari pelayanan rawat jalan dan rawat inap di RS IPI medan angka keempat dari gab terbesar. Sehingga pelanggan internal mengharapkan pengadaan letak unit rekam medis yang strategis. Dalam penyelenggaran rekam medis yang bermutu dan efektif diperlukan adanya sarana penunjang yang memadai, diantaranya adalah kondisi tata letak unit rekam medis dan ruang penyimpanan berkas rekam medis (Dinia dan Nudji, 2017).

5. Hasil penelitian kesesuain informasi merupakan angka ke 5 tertinggi gab dari harapan pelanggan internal, sehingga pelanggan internal mengharapkan adanya komunikasi yang baik antar sesama pelanggan internal RS IPI Medan.

Komunikasi diartikan sebagai satu proses yang terdiri dari "pengiriman, mengirimkan pesan melalui saran kepada penerima yang menanggapi”. Pengertian ini menunjukan tiga unsur pokok komunikasi yaitu pengirim, pesan, dan penerima. Jikalau salah satu unsur tidak ada, maka tidak akan mungkin terjadi komunikasi. Komunikasi terjadi dalam lingkungan organisasi disebut komunikasi internal (Lestari dan Kasmirudin, 2017).

\section{KESIMPULAN}

Berdasarkan analisis dari pengolahan data yang telah dilakukan, maka dapat di tarik kesimpulan Terdapat 5 atribut pelayanan yang diprioritakan untuk dilakukan perbaikan berdasarkan hasil 5 gab terbesar, antara lain adalah ruang penyimpanan yang luas, keamanan penyimpanan berkas rekam medis, jumlah pegawai, perlengkapan rekam medis, kesesuaian informasi, Letak gedung URM yang strategis dari rawat jalan dan rawat inap.Pada hasil QFD (Hows) dapat dilihat bahwa untuk menjawab kebutuhan pelanggan internal sehingga dapat 
meningkatkan kualitas layanan unit rekam medis.

\section{SARAN}

- Kepada Pihak Rumah Sakit

Diharapkan dapat memenuhi kebutuhan pelanggan internal, seperti perluasan penyimpanan, penambahan jumlah pegawai, melengkapi kebutuhan penyimpanan berkas rekam medis dan membuat letak unit rekam medis yang strategis untuk meningkatkan mutu pelayanan dan produktivitas pelanggan internal.

- Peneliti Selanjutnya

Diharapkan dapat melanjutkan penelitian untuk mengetahui tingkat kepentingan dari kebutuhan pelanggan internal.

\section{DAFTAR PUSTAKA}

Dinia. R.M dan Nudji. B. (2017). Perancangan ulang tata letak ruang unit rekam medis dalam peningkatan produktivitas kerja perekam medis di rumah sakit paru surabaya. http://Perancangan_Ulang_Tata_Letak _Ruang_Unit_Rekam_Medis.pdf. Di akses : tanggal 15 Juni 2018. Jam 22.00 WIB.

Isgiyanto, A. (2009). Teknik Pengambilan Sampel. Yogyakarta: Mitra Cendikia Press.

Lestari. G dan Kasmirudin. (2017). Pengaruh Komunikasi Internal dan Motivasi Kerja Terhadap Kinerja Karyawan Industri Media.
Http://205395-pengaruh-komunikasiinternal-dan-motivasi.pdf. Diakses tanggal 18 Juli 2018 jam 16.30 WIB.

Notoadmodjo, S. (2012). Metodologi Penelitian Kesehatan. Jakarta: Rineka Cipta.

Novi, prihat. (2010). Hubungan antara Tingkat Pengetahuan dan Sikap Dengan Kesiapan Wanita Premenopause Menghadapi Menopause di Wilayah Kelurahan Gisikdrono Kecamatan Semarang Barat. Http://jtptunimus-gdl-S1-2008noviprihat-178-4-bab3.pdf. Diakses: tanggal 28 Juni 2018 jam 07.00 WIB.

Peraturan Bersama Menteri Kesehatan dan Kepala Badan Kepegawaian Negara. (2013). Kepegawaian Rumah Sakit. Jakarta: Peraturan Bersama Menteri Kesehatan dan Kepala Badan Kepegawaian Negara.

Pohan. I. (2015). Jaminan Mutu Layanan Kesehatan. Jakarta: EGC.

Sugiyono. (2013). Metodologi Penelitian Pendidikan Pendekatan Kualitatif dan Kualitatif. Bandung: Alfabeta.

Undang-undang Nomor 36 Tahun 2009.Tentang Kesehatan. Jakarta: Kemenkes RI.

Wiguna A.D. (2015). Tinjauan Pelaksanaan Penyimpanan berkas guna menunjang efektivitas pelayanan rekam medis di rumah sakit umum saraswati cikampek. http://TugasAkhir(PDF)-Scribd-pdf. Diakses : tanggal 17 Juli 2018 jam 18.00 WIB

Wijaya, T. (2018). Manajemen Kualitas Jassa Desain Servqual. Jakarta. 